Revista de Economia Política, vol. 36, no 3 (144), pp. 603-621, julho-setembro/2016

\title{
Fundamentos macroeconômicos nas perspectivas de Marx e Keynes: contribuições para a heterodoxia
}

\author{
Macroeconomic foundations in the perspectives of Marx \\ and Keynes: contributions to the heterodox thought
}

PEDRO GARRIDO DA COSTA LIMA

ADRIANA MOREIRA AMADO

MARIA DE LOURDES ROLLEMBERG MOLLO*

\begin{abstract}
RESUMO: A necessidade de definir fundamentos microeconômicos para os modelos macroeconômicos, presente no pensamento dominante na economia contemporânea, pode ser questionada com base em diferentes abordagens teóricas. Posições como as de Marx e Keynes permitem a apreensão das ações dos agentes econômicos (grupos ou classes) como influenciadas e limitadas pelo ambiente social e macroeconômico, fornecendo visões de fundamentos macroeconômicos da microeconomia, ao invés da visão ortodoxa de fundamentos micro da macroeconomia. Essa forma de apreensão lança luz sobre diferenças de perspectivas da heterodoxia quando se trata de intervir sobre o contexto macroeconômico.
\end{abstract}

PALAVRAS-CHAVE: Marx; Keynes; macrofundamentos; heterodoxia.

ABSTRACT: The need to define microeconomic foundations for macroeconomic models, which is present in the mainstream thinking in contemporary economics, can be questioned on the basis of different theoretical approaches. Positions like those of Marx and Keynes permit the comprehension of the actions of economic agents (groups or classes) as influenced and limited by the social and macroeconomic environment, providing views of macroeconomic foundations of microeconomics, instead of the orthodox view of microfoundations of macroeconomics. This comprehension sheds light on distinct perspectives in heterodox thought regarding the intervention in the macroeconomic context.

KEYWORDS: Marx; Keynes; macrofoundations; heterodoxy.

JEL Classification: E11; E12; B50.

* Doutor em Economia pela Universidade de Brasília - UnB. E-mail: pedrogarrido@gmail.com; Professora do Departamento de Economia da Universidade de Brasília - UnB. E-mail: uctpama@unb. br; Professora do Departamento de Economia da Universidade de Brasília - UnB. E-mail: mlmollo@ unb.br. Submetido: 21/Outubro/2014; aprovado: 16/Julho/2015. 


\section{INTRODUÇÃO ${ }^{1}$}

O pensamento dominante na economia contemporânea tem como agenda de pesquisa o desenvolvimento de modelos com base em fundamentos microeconômicos para a análise de aspectos macroeconômicos na economia. Essa necessidade pode ser questionada com base em desenvolvimentos próprios da economia mainstream. É possível cogitar, ademais, a formulação de fundamentos macroeconômicos para o comportamento microeconômico dos agentes na economia.

As contribuições teóricas de Marx e Keynes podem ser consideradas significativas para a formulação de fundamentos macroeconômicos e para o entendimento das ações e motivações no sistema econômico capitalista. Elementos essenciais das duas perspectivas, como as relações sociais que permeiam o capitalismo, a incerteza e as convenções, presentes em trabalhos originais de Marx e Keynes e em outros autores, permitem a busca de outras formas de teorização econômica sobre as ações dos agentes na economia. Dessa forma, para entender o comportamento de agentes econômicos e grupos sociais, torna-se essencial compreender os fundamentos sociais e macroeconômicos delimitadores das ações nas sociedades capitalistas.

Além desta introdução, o presente artigo tem a seguinte estrutura: são apresentados, na primeira seção, os fundamentos microeconômicos no mainstream e algumas críticas a esses fundamentos. Na segunda seção, são analisados os fundamentos macroeconômicos na perspectiva de Marx. Os fundamentos macroeconômicos conforme Keynes são discutidos na terceira seção. As contribuições das perspectivas marxista e pós-keynesiana para a heterodoxia são avaliadas na quarta seção. Por fim, são apresentados comentários finais sobre os assuntos discutidos.

\section{FUNDAMENTOS MICROECONÔMICOS NO PENSAMENTO DOMINANTE E CRÍTICAS}

A visão predominante na economia ortodoxa quanto aos fundamentos microeconômicos relaciona o surgimento desse programa de pesquisa e método para construção de modelos teóricos com a conhecida crítica feita por Lucas (1976) aos modelos macroeconométricos. Nessa perspectiva, que passa a ser influente junto com a escola novo-clássica e a utilização generalizada de expectativas racionais, procuram-se microfundamentos para a teoria macroeconômica, buscando-se parâmetros profundos decorrentes do comportamento de otimização individual dos agentes econômicos. A determinação do resultado agregado pela incorporação de microfundamentos definidos pelo comportamento otimizador de agentes individuais racionais geraria a necessidade de desenvolver modelos com agentes repre-

\footnotetext{
${ }^{1}$ Os autores agradecem as sugestões e comentários feitos por dois pareceristas anônimos que foram fundamentais para clarificar e expandir diversos elementos do presente artigo. Imprecisões e defeitos remanescentes são de responsabilidade dos autores.
} 
sentativos $^{2}$. Essa visão tornou-se dominante na ortodoxia e foi adotada pelas escolas de ciclos reais e novo-keynesiana.

A narrativa-padrão sobre os microfundamentos na teoria econômica pode ser reconsiderada com base na história do pensamento econômico, segundo Duarte e Lima (2012), para quem essa narrativa serve para sustentar um argumento metodológico que é historicamente particular. Essa forma de relacionar as interações micro e macroeconômicas não é a única, nem a primeira a ser proposta. Essa perspectiva também está sujeita a dificuldades associadas à agregação. $\mathrm{O}$ teorema de Sonnenschein-Mantel-Debreu do início dos anos 1970 já mostrava que as restrições que geram funções de demanda individuais bem-comportadas não levam a funções de demanda agregadas com essas mesmas propriedades. Para evitar esse problema, ou se supõe uma economia composta de indivíduos idênticos ou um agente que represente toda a economia ${ }^{3}$, solução esta seguida pela ortodoxia.

Apesar dessa opção metodológica, Hoover (2012) distingue, na literatura econômica a partir do início do século XX, dois outros programas de pesquisa com base em microfundamentos (o de agregação para modelos macroeconométricos de Klein e o de equilíbrio geral avançado por Hicks), além do programa que se utiliza do conceito de agente representativo. Ele considera alguns autores importantes que se encontram na pré-história dessa abordagem (Frisch e Keynes). Com base nessa reconstrução histórica, explica-se que o programa de pesquisa do agente representativo incorpora "eliminative microfoundations", em que se busca suprimir a macroeconomia em benefício da microeconomia. Já os outros dois programas de pesquisa, que eram formas alternativas dentro da perspectiva ortodoxa, não implicavam necessariamente essa eliminação. Kirman (1992) argumenta em favor da impossibilidade de redução do comportamento de um grupo de agentes heterogêneos a um indivíduo representativo, mesmo que esses agentes sejam maximizadores de utilidade. A suposta conveniência analítica do agente representativo é injustificada e leva a resultados falsos, sem resolver problemas de agregação. A busca por equilíbrio único e estável levou os macroeconomistas a adotarem o agente representativo para tentar desviar da dificuldade advinda do teorema de Sonnenschein-Mantel-Debreu ${ }^{4}$. Ainda assim, mesmo que essa dificuldade seja desconsiderada,

\footnotetext{
${ }^{2}$ Cabe distinguir o contexto da utilização de agentes representativos na macroeconomia da maneira como essa noção surge na microeconomia. De acordo com Screpanti e Zamagni (2005), Marshall teve grande influência na teoria econômica a partir do uso do método de equilíbrio parcial em que utilizava os conceitos de indústria e de firma representativa. A indústria produziria bens iguais, enquanto a firma representativa denotaria uma firma média que reproduzia as características mais importantes da indústria.

${ }^{3}$ A metodologia de agentes representativos domina as outras abordagens de microfundamentos, no entanto, trabalha apenas com o comportamento único desse agente hipotético. Essa metodologia, ao não levar em conta a heterogeneidade entre agentes, desconsidera problemas de coordenação.

${ }^{4}$ Kirman (1992) salienta que a agregação de indivíduos bem-comportados, que têm curva de demanda com equilíbrio único e estável, não necessariamente reproduz essas propriedades. O axioma fraco da preferência revelada não é obedecido nessa agregação.
} 
Kirman nota que a maximização individual não gera racionalidade coletiva, nem a existência dessa racionalidade implica indivíduos racionais. Também a reação do agente representativo a mudanças em parâmetros (como as causadas por políticas governamentais) pode não ser igual à reação agregada dos indivíduos representados por esse agente. Podem ainda existir situações em que o agente representativo escolheria diferentemente de todos os indivíduos representados. Dessa forma, “to infer society's preferences from those of the representative individual, and to use these to make policy choices, is illegitimate". Kirman (1992, p. 125) aponta que:

the assumption of a representative individual is far from innocent; it is the fiction by which macroeconomics can justify equilibrium analysis and provide pseudo-microfoundations.

Além das dificuldades associadas a agregação e heterogeneidade, a sinalização proveniente das variáveis macroeconômicas para os indivíduos permite questionar os microfundamentos presentes na ortodoxia e conferir relevo à necessidade de fundamentos macroeconômicos. Nesse sentido, Hahn (2003) critica a noção de agentes representativos na macroeconomia e indica, utilizando a lógica de otimização dos agentes econômicos, como é necessário discutir macrofundamentos para o estudo da microeconomia, com destaque para a situação de busca no mercado de trabalho e a sinalização proveniente dos índices de preços. Para Hahn (2003, p. 230):

macro-variables act as measures of particular externalities and so must be considered by micro theory. [...] changes in the values of macro variables may lead to structural changes in the [General Equilibrium] description of an economy.

Assim, as variáveis macroeconômicas são sinais para os agentes, quando não se tem informação perfeita para realizar previsões corretas do mercado no longo prazo. O agente não pode observar todos os preços na economia e formar expectativas sobre o valor futuro de cada preço.

O reconhecimento de que a microeconomia e a macroeconomia são constituídas por metodologias e campos teóricos separados, mas com importantes inter-relações, foi apontado por autores como Bresser-Pereira e Lima (1996), para quem a macroeconomia não pode ser reduzida à microeconomia. Essa abordagem associa o método histórico-indutivo à primeira disciplina e o hipotético-dedutivo à segunda, o que não limita o pensamento macro a ser deduzido de ações individuais. Ademais, identidades macroeconômicas são consistentes com diversos comportamentos micro definidos $a d h o c$. Defendem os autores que a maximização individual e o market-clearing da teoria neoclássica constituem caso específico de microfundamentação. A fundamentação micro pode ser derivada, mais amplamente, de hi- 
póteses associadas ao comportamento de classes e grupos e da concorrência imperfeita, sem maximização ou equilíbrio 5 .

De fato, o caráter discutível dos microfundamentos da macroeconomia torna-se mais claro com a consideração da natureza do sistema capitalista que pode ser derivada das formulações de Marx e Keynes. Esses autores desenvolveram contribuições significativas para a heterodoxia no pensamento econômico, de acordo com Mollo (2003) e Amado (1992), em especial quanto à não neutralidade e endogeneidade da moeda. As concepções de Marx e de Keynes possibilitam contestar a pertinência de fundamentação microeconômica e propiciam base para a fundamentação macroeconômica do comportamento microeconômico nas economias capitalistas.

\section{FUNDAMENTOS MACROECONÔMICOS NA PERSPECTIVA DE MARX}

Para Marx, o capitalismo constitui sistema produtor de mercadorias em que se busca incessantemente o lucro máximo pela produção de mais-valia. A riqueza é definida por imensa acumulação de mercadorias. Todos são compradores e vendedores, e o valor-trabalho e o dinheiro passam a ser relações fundamentais na organização social do capitalismo.

Marx (1857-58) tem como ponto de partida teórico os indivíduos produzindo em sociedade e a totalidade ${ }^{6}$ no sistema capitalista ${ }^{7}$. A produção é entendida como certo corpo social, um sujeito social em atividade em uma totalidade maior ou menor de ramos de produção, em que ocorre apropriação da natureza pelo indivíduo dentro de e mediada por determinada forma de sociedade.

Nesse sentido Lukács (1984) destaca que Marx, mesmo conferindo prioridade ontológica à esfera econômica, considera a sociedade como um complexo composto por rede de complexos heterogêneos e parciais, entre os quais classes sociais, grupos e sistemas de mediação relativamente autônomos (como direito e Estado). As ações singulares, a consciência e seus conteúdos não são concebidos como produto imediato da estrutura econômica, mas da totalidade social, incluindo as determinações extraeconômicas. Indivíduos reagem com decisões alternativas ao próprio mundo circundante, que constitui a base de todos os complexos de media-

\footnotetext{
${ }^{5}$ Nesse sentido, Bresser-Pereira e Lima (1996) mencionam as abordagens clássica-marxista e póskeynesiana.

${ }^{6}$ Cabe notar que o conceito de totalidade, ressalta Jay (1984), foi recuperado e enfatizado pelo marxismo ocidental no debate teórico e prático, com origem em Lukács. Seja com inspiração hegeliana ou antihegeliana, conceitos como alienação, mediação, objetificação e reificação, assim como o papel da cultura, foram importantes elementos de discussão entre os autores associados a essa tradição.

${ }^{7} \mathrm{Na}$ Introdução à Crítica da Economia Política, Marx (1857-58), por meio do método dialético, explica que, ao se partir da totalidade e chegar de novo a ela após abstrações por meio do pensamento, é obtida rica totalidade de determinações e relações diversas, e não uma representação caótica do todo. A realidade concreta pensada passa a ser uma "síntese de múltiplas determinações".
} 
ção e diferenciação. Quando as relações econômicas são compreendidas como totalidade dinâmica e concreta, evidencia-se que homens fazem sua própria história, mas os resultados do decurso histórico são diversos e podem ser opostos aos objetivos visados pelos inelimináveis atos de vontade dos indivíduos.

Entender um modo de produção, para Marx, requer a apreensão da forma como os homens se organizam para prover sua existência, o que leva ao processo de trabalho. Este, no capitalismo, produz mercadorias. A mercadoria apresenta duas dimensões correspondentes a dois tipos de trabalho diferentes. O trabalho concreto confere utilidade própria às mercadorias, que satisfazem as necessidades "do estômago e da fantasia" na condição de valor de uso. A propriedade comum a todas as mercadorias é a de ser produto do trabalho humano abstrato. Sob esta dimensão não existe um único átomo de valor-de-uso nelas, não há nenhum trabalho útil. O trabalho despendido e cristalizado em cada mercadoria é a medida socialmente necessária para a produção daquele bem. $\mathrm{O}$ valor de troca revela-se na relação quantitativa entre valores-de-uso diferentes, nas suas proporções de troca no tempo. O que vai importar é a quantidade de tempo de trabalho social contido determinando a magnitude do valor da mercadoria ${ }^{8}$.

A troca direta não pode existir se cada mercadoria for valor e valor de uso ao mesmo tempo. Essa contradição pode ser evitada se algo representar, em geral, o valor de todas as outras mercadorias. Assim, as mercadorias podem ser valores de uso elas mesmas e valores quando confrontadas com uma única mercadoria, que passa a ter como valor de uso a explicitação do valor de troca. A interação espontânea entre as mercadorias isola uma de seu conjunto, excluindo-a da circulação das outras mercadorias para tornar-se a representante independente do valor. Apenas a ação social de todas as outras mercadorias elege, portanto, uma determinada para nela representarem seus valores (Brunhoff, 1976; Saad Filho, 2002).

Nas sociedades capitalistas, dado seu caráter mercantil, os trabalhos são privados, mas precisam ser divididos socialmente, o que é feito por meio da venda contra dinheiro. Nesse processo, trabalhos privados são socialmente validados. Assim, a característica do sistema produtor de mercadorias é que valor e dinheiro são relações sociais e determinam a forma de inserção social no capitalismo9. Como todos os indivíduos são compradores e vendedores de mercadorias, a divisão do trabalho é feita por meio do valor e do dinheiro. Dessa forma, os trabalhadores, após processo histórico de subsunção real e formal do trabalho, passam a não ter outro meio para viver em sociedade a não ser o de ofertar sua força de trabalho como mercadoria para os capitalistas. Como esta classe detém os meios de produção e paga aos trabalhadores o valor equivalente ao custo de reprodução da força

\footnotetext{
${ }^{8}$ A partir da consideração desse caráter dual do trabalho na mercadoria, Postone (1993) destaca que podem ser distinguidas duas totalidades sociais expressas pela categoria do capital, a abstrata formal e a substantiva, que representam, respectivamente, as duas formas de trabalho expressas na mercadoria, abstrato e concreto.

${ }^{9}$ Para Itoh e Lapavitsas (1999), o dinheiro é relação social que define, de maneira alienada, a inserção social dos indivíduos como nexus rerum (o elemento que une) do capitalismo.
} 
de trabalho, os capitalistas podem apropriar-se do trabalho ou valor excedente produzido pelos trabalhadores. Assim, o sistema é produtor de mais-valia, ao gerar lucro pela exploração do trabalho excedente ${ }^{10}$.

Observe-se que, nesta visão, o trabalho e o valor que o contém, assim como o dinheiro que o representa, são formas sociais fundamentais de organização da sociedade e das ações dos indivíduos. Sobre a importância do trabalho, diz Postone (2008, p. 128), "the Marxian contradiction should be understood as a growing contradiction between the sort of labour people perform under capitalism and the sort of labour they could perform if value were abolished and the productive potential developed under capitalism were reflexively used to liberate people from the sway of the alienated structures constituted by their own labour". Sobre a importância do dinheiro, diz Marx (1857-58), de forma crítica, que os homens alienam suas próprias decisões a "uma coisa", tornando-a uma relação social.

Nesse processo de produção e circulação, o valor e o dinheiro resolvem a contradição privado-social de uma sociedade na qual os trabalhos são realizados de forma privada, e via divisão social, sem que se elimine essa contradição, articulando produção e circulação por meio da realização da divisão social do trabalho de forma indireta. Assim, valor e dinheiro tornam-se relações sociais segundo as quais o dinheiro é excluído socialmente para cumprir o papel de equivalente geral e o critério de validação social dos trabalhos privados é a conversão em dinheiro. Esse teste é feito por meio do dinheiro, mas se dará conforme possibilidade ou não de venda a determinado preço.

Em Marx, vão ser observados dois tipos de circulação do dinheiro (D). A forma simples, em que o objetivo da troca é o valor de uso proporcionado por uma mercadoria $(\mathrm{M})$, descreve-se por:

$$
M-D-M
$$

A circulação do capital tem como objetivo o valor de troca aumentado. O capital é o dinheiro que se valoriza e fundamenta o objetivo microeconômico de lucro incessante das firmas. Embora sejam mantidos equivalentes nas trocas, verifica-se a geração de excedente na apropriação de mais-valiaa ${ }^{11}$ quando o dinheiro se torna capital. A valorização do capital é o que mantém o capitalista enquanto tal. Assim, é a lógica macroeconômica do capitalismo enquanto modo de produção que forma o comportamento do capitalista:

$$
M-D-M^{\prime}
$$

\footnotetext{
${ }^{10}$ Cabe notar que os valores trocados são equivalentes, então não se trata de roubo ou trocas a valores diminuídos. Assim, de um ponto de vista macroeconômico, ressalta Bellofiore (2004), as trocas não geram valor, apenas o redistribuem.

${ }^{11}$ Uma sociedade cujo objetivo essencial é a troca de produtos por produtos entre indivíduos isolados não corresponde à natureza do capitalismo. Como afirmou Marx (1857-58, p. 54), o "caçador e o pescador, singulares e isolados, pelos quais começam Smith e Ricardo, pertencem às ilusões desprovidas de fantasia das robisonadas do século XVIII".
} 
Sendo D' maior do que D. A expansão dessa fórmula revela o conteúdo presente na circulação do capital ${ }^{12}$, na qual o dinheiro avançado compra as mercadorias força de trabalho (FT) e meios de produção (MP), as quais são utilizadas no processo de produção $(\mathrm{P})$ que gera mercadorias com mais valor ( $\left.\mathrm{M}^{\prime}\right)$ do que o inicial, quando convertido em dinheiro (D'):

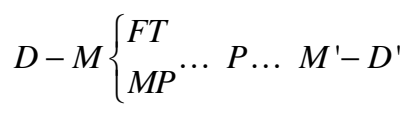

Os conceitos definidos por Marx suscitam a avaliação de que pode existir autonomia relativa da esfera da circulação em relação à produção. O desenvolvimento do crédito e do capital fictício, no processo de financeirização e descolamento do lastro em trabalho, constitui exemplo dessa autonomização do capital em busca de maior lucro e menos limites, como estuda Mollo (2011). Não obstante, a relativa autonomia entre preço e valor e entre circulação e produção é limitada pela lei do valor. As mercadorias precisam ser convertidas em dinheiro para provar a validade social do trabalho privado dispendido e realizar assim a divisão social do trabalho. Mas a lei do valor pode também se impor de maneira violenta, por meio de crises, que são fenômenos inerentes ao capitalismo.

Dessa forma, a determinação social do trabalho por meio da relação de valor consubstancia-se, de um ponto de vista social e econômico, como exigência sobre o comportamento dos indivíduos no capitalismo.

A dinâmica na esfera da produção não é menos sujeita a condicionantes macroeconômicos à ação dos agentes e enseja trajetórias de crises. Em razão da busca por lucro, objetivo do capitalismo, e superlucro, sob pressão da concorrência intercapitalista, há tendência a aumentar a mais-valia absoluta e, principalmente, a relativa, para o que se impõe a necessidade de investimento em desenvolvimento tecnológico que amplie a produtividade dos trabalhadores e reduza os custos, em particular o de reprodução da força de trabalho. Revela-se aí o caráter excludente do capitalismo por meio da concentração e centralização de capitais e do aumento do desemprego, ao qual está associado o exército industrial de reserva ${ }^{13}$. A mais-valia relativa decorre do progresso tecnológico, o qual, reduzindo custos, particularmente o de reprodução da força de trabalho, permite aumentar o lucro. No entanto, esse investimento é caro, o que conduz à concentração e centralização do capital. O progresso técnico é poupador de mão de obra, levando ao desemprego. O aumento da produção não é acompanhado pela capacidade de consumo. Ocorre, portanto, caso em que o comportamento individual de capitalistas, fruto da

\footnotetext{
${ }^{12}$ Essa circulação ainda está associada ao capital-dinheiro e o crédito, este que potencializa o processo produtivo, além do capital mercantil, que possibilita a venda de mercadorias aos consumidores finais, conforme Marx $(1885,1894)$.

${ }^{13} \mathrm{O}$ exército industrial de reserva impõe freios ao crescimento dos salários e disciplina os trabalhadores em razão do medo de ficar desempregado.
} 
lógica do sistema ao buscar maior lucro em meio ao processo de concorrência, é contraditório com relação ao desenvolvimento sustentado do sistema.

Nesse sentido, o ambiente macroeconômico constitui-se, para Marx, como maior do que a soma de suas partes constituintes, de acordo com Bellofiore (2004). Os resultados macro podem ser não apenas anteriores, apresentando-se como responsáveis pelo comportamento micro das classes, mas também opostos aos interesses e comportamento micro. A precedência e autonomia da lógica macroeconômica significa que a pesquisa precisa primeiramente descobrir as leis de sobrevivência e crescimento do sistema e depois mostrar como o comportamento dos indivíduos obedece ou contradiz essas leis. A originalidade de Marx está na fundamentação macrossocial dos comportamentos.

Nessa perspectiva macrossocial, a produção de mais-valia aparece em Marx de maneira explicitamente macroeconômica. A extração de trabalho vivo e, portanto, de trabalho abstrato, caracteriza-se como processo macro incorporado no contexto maior das relações capital/trabalho, uma vez que a luta de classes entre a totalidade da classe trabalhadora e a totalidade da classe capitalista determina a intensidade do processo produtivo e a duração da jornada de trabalho. Apenas a partir dessa consideração macro é que se torna possível entender a constituição da renda monetária total como resultado do trabalho abstrato.

\section{FUNDAMENTOS MACROECONÔMICOS NA PERSPECTIVA DE KEYNES}

É possível evidenciar fundamentos macroeconômicos para a ação dos agentes individuais a partir de características da sociedade capitalista na concepção mais heterodoxa de Keynes e dos pós-keynesianos. A operação dos agentes em uma economia monetária de produção que é inerentemente incerta pressupõe a emergência de convenções e de determinada psicologia social nas quais estão ancoradas as expectativas e o comportamento dos agentes.

A perspectiva de Keynes (1936), na Teoria Geral, constitui exemplo, segundo Dow (1996), de abordagem holística em que é empreendida combinação logicamente consistente entre análise micro e macro, ainda que os microfundamentos não sejam exatamente equivalentes aos da teoria neoclássica. Keynes utilizou fundamentos microeconômicos próximos à visão neoclássica, para combater essa abordagem em seu próprio terreno, mostrando a inadequação da Lei de Say mesmo com fundamentos neoclássicos, conforme ressalta Chick (1983). Também as contribuições teóricas de autores pós-keynesianos para o entendimento das relações entre os aspectos micro e macroeconômicos das economias capitalistas remontam ao artigo de Weintraub (1956), em que são encontradas referências explícitas a microfundamentos em período anterior mesmo à preocupação da ortodoxia novo-clássica.

A preocupação com o comportamento humano em sociedade e a lógica das ações neste contexto social marcam a base do pensamento econômico descrito por Keynes (1937), ao elaborar explicitamente as concepções que haviam sido avançadas na Teoria Geral (1936). O autor começa a sua análise econômica a partir da 
ênfase na lógica do comportamento humano em um mundo onde nada está muito definido. Os agentes econômicos não são autômatos e decidem e agem segundo a vida em uma sociedade cuja trajetória é indeterminada. As razões para a existência da moeda decorrem de uma necessidade real na sociedade econômica que não diz respeito somente à circulação.

A teoria neoclássica parte de um mundo que pode ser descrito de acordo com algum cálculo atuarial, eliminando-se a incerteza, pois o mundo seria definido conforme determinadas funções de probabilidade. Essa interpretação dos princípios do comportamento dos agentes na economia torna-se equivocada ao subestimar o papel da dúvida e do medo na sociedade. Segundo Keynes, a teoria (neo)clássica desconsidera a diferença que a sua abstração provoca entre a teoria e a prática e o caráter das falácias para as quais ela é levada, mesmo admitindo, eventualmente, a precariedade do conhecimento. Assim, Keynes (1937, p. 115) assevera:

I accuse the classical economy theory of being one of these pretty, polite techniques which tries to deal with the present by abstracting from the fact that we know very little about the future.

A preocupação com o comportamento humano em sociedade e a lógica das ações neste contexto social marcam a base do pensamento econômico de Keynes. De fato, "we have, as a rule, only the vaguest idea of any but the most direct consequences of our acts". Algumas vezes a preocupação é com um futuro remoto; e entre as principais angústias humanas relacionadas a esses momentos está a questão econômica central da riqueza. O objetivo da acumulação de riqueza é produzir resultados num futuro indefinidamente distante, em uma atividade contínua e incessante. A constatação de que o futuro é flutuante, vago e incerto torna inadequados os métodos da teoria clássica ${ }^{14}$.

A noção de conhecimento incerto é essencial para o entendimento da teoria de Keynes e não significa distinção entre o que é certo ou apenas provável. Os fenômenos sociais (como guerras, preços futuros, uso de tecnologia ou alocação de riqueza) não apresentam base científica para o cálculo de probabilidades. Não há como prever com certeza: "We simply do not know". Mesmo assim, a impulsão para a ação e decisão leva os indivíduos a atuarem da melhor maneira possível para passar por cima desses problemas, recorrendo ao cálculo de vantagens e desvantagens esperadas, segundo probabilidades atribuídas. Ou seja, ainda que o mundo acabe sendo descrito em termos de probabilidades pelos agentes, esta base para atuação é muito fraca e representa maneira de lidar com a incerteza, mas não uma qualidade do próprio mundo.

A racionalidade, dada essa condição da economia, requer a constituição de convenções, de acordo com Keynes. Configura-se, dessa maneira, uma resposta

\footnotetext{
${ }^{14}$ Se, no mundo capitalista, a acumulação não constituísse uma característica fundamental e os bens fossem consumidos imediatamente depois de produzidos, aqueles métodos seriam aplicáveis.
} 
racional dos seres humanos ("rational, economic men") em face da incerteza. As técnicas desenvolvidas para lidar com a incerteza são: 1) o presente é um guia melhor para o futuro do que um cândido exame da experiência passada, em que são ignoradas as projeções sobre mudanças futuras desconhecidas; 2) a opinião sobre preços e o caráter da produção existentes são baseados no resumo correto de previsões futuras, devendo-se aceitá-las como tal a não ser que haja novidades relevantes; e 3) como julgamento individual é irrelevante, os indivíduos agem copiando o comportamento majoritário ou mediano. A psicologia de uma sociedade de indivíduos onde cada um procura copiar os outros leva a julgamento chamado convencional. Esses princípios sobre o comportamento humano também atuam quando há mudanças repentinas e violentas, que podem trazer nova base de convenções.

A moeda surge como necessidade do mundo econômico para fazer frente à incerteza. Por isso, ocupa as funções de unidade de conta, meio de circulação (ou troca) e reserva de valor. Essas funções estão intimamente associadas na concepção de Keynes. Sendo reserva de valor, a moeda não possui rendimento, e parece irracional mantê-la (1937, pp. 115-116):

Why should anyone outside a lunatic asylum wish to use money as a store of wealth? [...] partly on reasonable and partly on instinctive grounds, our desire to hold money as a store of wealth is a barometer of the degree of our distrust of our own calculations and conventions concerning the future. [...] The possession of actual money lulls our disquietude; and the premium which we require to make us part with money is the measure of the degree of our disquietude.

Assim, a principal decorrência das flutuações no estado de confiança da economia é a variação do prêmio concedido para os agentes abrirem mão de entesourar moeda. Este prêmio é a taxa de juros, que varia conforme a preferência pela liquidez ou propensão a entesourar e ajusta, na margem, a demanda e a oferta de entesouramento. A taxa de juros em Keynes é um fenômeno monetário, não um equilíbrio entre poupança e investimento como na teoria neoclássica dos fundos emprestáveis. As flutuações no investimento não estão relacionadas à disposição de poupar determinada renda ou de condições técnicas da eficiência marginal do capital.

Em uma economia monetária, a moeda não é apenas um meio de circulação, mas também um ativo, um meio de conservar riqueza, sendo seu principal atributo a capacidade de liquidar débitos e representar poder de compra em sua forma mais pura. É capaz de desempenhar esta função por ser o ativo mais líquido da economia. A função unidade de conta merece destaque, pois os contratos na economia são firmados em termos monetários. O dinheiro é mantido também para fazer uma ponte entre intervalos definidos entre transações monetárias como representação de riqueza, um ativo que pode ser guardado para ser gasto em alguma data futura. A existência da demanda por dinheiro como ativo afeta a demanda e os preços de 
outros ativos, que são formas alternativas de conservar riqueza com diferentes atributos, sendo determinante para o investimento a escolha entre ativos líquidos (como moeda e títulos financeiros) e bens de capital ${ }^{15}$.

A partir dessa visão de mundo, de acordo com Davidson (1972), Keynes rejeita três axiomas da teoria neoclássica que não correspondem à realidade das economias monetárias. São rejeitados o axioma da substituição (tudo pode ser substituído por outra coisa em algum grau), o axioma dos reais (toda atividade econômica é motivada e conduzida olhando-se variáveis reais, desconsiderando a moeda) e o axioma da ergodicidade (processos econômicos podem ser repetidos, replicados e revertidos). A observação da incerteza implica um mundo indeterminado. O dinheiro não tem substitutos e toda avaliação do valor é feita por meio de preços, que são monetários, o que descarta o pensamento real em qualquer mercado (como o de bens, o monetário e o de trabalho).

Esses condicionantes das economias monetárias influenciam a necessidade de considerar que o ambiente macroeconômico é determinante nas escolhas individuais. De acordo com Kregel (1987, p. 528)

The 'non-ergodicity' of the system then ultimately results from the fact that individual actions are constrained by the actions of other individuals which cannot be predicted with certainty and thus when taken together form an aggregate or global or macroeconomic constraint which is not the simple, linear, and therefore predictable summation of individual behaviour. Thus is it not macroeconomics that has to be brought into close touch with microeconomics, but rather one must try to formulate a macrofoundation for uncertain individual decisions.

Carvalho (1992) defende que a abordagem dos pós-keynesianos está ancorada nessa interpretação fundamental dos textos de Keynes e define seis princípios das economias monetárias de produção, que seriam características do capitalismo para essa escola. São os princípios da produção, da estratégia dominante, da temporalidade da atividade econômica, da não ergodicidade, da coordenação e das propriedades da moeda. Esses princípios fornecem fundamentos, no contexto da incerteza e do comportamento convencional, às ações dos agentes econômicos.

Cabe destacar, no princípio da produção, que a firma tem uma individualidade particular como agente econômico, e difere em objetivos com relação a outros

\footnotetext{
${ }^{15}$ Keynes (1936, cap. 17) fornece interpretação da escolha sobre o emprego da riqueza, ao elaborar, como ressaltam Chick (1983) e Carvalho (1992), uma teoria de escolha de ativos pela comparação da moeda definindo a condição de ativo da moeda perante os outros na economia. Em equilíbrio, os rendimentos esperados (taxas de retorno e de apreciação, deduzidos os custos de carregamento) a serem obtidos pelos proprietários dos ativos (não monetários) devem ser iguais à sua liquidez relativa quando comparados à moeda, de modo a igualar as vantagens marginais entre os ativos.

${ }^{16}$ Kregel (1987) argumenta que os fundamentos macroeconômicos para os comportamentos individuais resultam do papel da moeda e da incerteza fundamental na economia.
} 
agentes, como as famílias. O princípio da produção estabelece que esta é realizada pelas firmas com o propósito de se obter lucros. A firma não existe para fornecer utilidade ao empreendedor (entrepreneur) ou fabricar produtos para serem vendidos e garantirem outros produtos úteis; pois, de fato, o que se busca no capitalismo é a geração continuada e ampliada de lucro, de maneira semelhante ao considerado por Marx ${ }^{17}$.

O princípio da estratégia dominante admite a existência de poderes diferenciados dos agentes na dinâmica econômica. Os mercados de trabalho e poupança dependem das deliberações das firmas. Trabalhadores e poupadores se adaptam aos efeitos das decisões tomadas pelas empresas. Por outro lado, Keynes também enfatizou que o processo de investimento é dominado pelos bancos. A distribuição dos recursos produtivos é desigual entre os agentes. O controle de meios de produção não é acessível a todos, o que determina hierarquias patentes. Isto se deve para Keynes, principalmente, porque o capital é escasso em relação ao trabalho (ainda que durante booms o trabalho escasseie). Entretanto, a capacidade de ter acesso a recursos é a característica mais fundamental: firmas (ou capitalistas) podem dispor de crédito dos bancos e têm mais riqueza acumulada, o que as possibilita comandar mais riqueza na sociedade.

A noção de temporalidade da atividade econômica é outro princípio fundamental. As escalas de produção são decididas baseadas nas expectativas de demanda, pois a produção leva tempo. Durante o processo produtivo, os fatores produtivos são remunerados em dinheiro, que pode ser gasto em qualquer momento posterior. As firmas operam conjecturando sobre a demanda, fazendo com que a produção no capitalismo seja altamente especulativa.

O princípio da não ergodicidade está associado à proposição de Davidson (1972) de que Keynes rejeita o axioma da ergodicidade, um dos pilares da economia ortodoxa. A incerteza fundamental (não distribucional) implica a irreversibilidade do tempo e a inadequação da noção de tempo mecânico da teoria neoclássica. $\mathrm{O}$ tempo é histórico. Já as propriedades da moeda fazem dela o ativo mais líquido da economia e um ativo imprescindível para afetar os humores e decisões na economia. A moeda possui três propriedades, descritas por Keynes (1936): elasticidades de produção e substituição nulas e custo de carregamento zero.

O princípio da coordenação supõe que, dada a ausência de planos preestabelecidos, a avaliação das atividades produtivas só pode ser obtida ex post-facto, pela revelação do mercado, ou pelo resultado líquido agregado das decisões decentralizadas. Essa visão pós-keynesiana mostra como a incerteza, um fato macroeconômico, afeta as decisões individuais microeconômicas, em particular a decisão de investir. É também a incerteza que leva, por exemplo, a decisões individuais convencionais e imitativas.

\footnotetext{
${ }^{17}$ Como reconhece Keynes (1933), ao examinar a validade do circuito de circulação do capital, D-M-D', descrito por Marx.
} 


\section{CONTRIBUIÇÕES PARA A HETERODOXIA}

As abordagens de Marx e de Keynes, em especial nas formulações apresentadas anteriormente, mostram uma alternativa à metodologia do mainstream de derivar os fenômenos macro dos comportamentos microeconômicos. Ao fazer isso lançam luz sobre características essenciais do sistema econômico capitalista.

O método desses autores já se distancia do cartesianismo da escola neoclássica, conforme apresenta Dow (1996). Chick (2003) destaca o organicismo presente em Keynes, em razão de o autor considerar o sistema econômico como um todo orgânico. Já Marx (1857-58), com base no pensamento dialético, utiliza concepção associada à totalidade na análise econômica. Nessa visão total ou orgânica, o estudo dos fenômenos econômicos não pode prescindir da análise histórica, o que está associado essencialmente à heterodoxia, conforme Bresser-Pereira (2012) ${ }^{18}$.

De acordo com Dow (1996) e Howard e King (2001), ambas as formulações refutam o individualismo metodológico e o reducionismo da economia neoclássica. As contradições entre comportamento individual e os resultados agregados nas duas abordagens contrastam com os modelos que reduzem as perspectivas macroeconômicas a agentes representativos microfundamentados que funcionam em perfeito equilíbrio e coordenação, abstraindo até mesmo dos obstáculos à agregação de indivíduos já registrados pela pesquisa em equilíbrio geral. Existe, consequentemente, a possibilidade de falácia da composição e contradições a partir do comportamento dos agentes, o que explicita o caráter instável da economia capitalista observado na realidade. Ademais, o indivíduo não é considerado como unidade de análise apropriada, uma vez que a teoria é construída a partir de grupos ou categorias de agentes, no caso dos pós-keynesianos e a partir de classes sociais para os marxistas.

Com relação, por exemplo, às firmas na economia capitalista, notam-se interpretações mais voltadas à realidade da concorrência capitalista, em contraposição à visão neoclássica. Os autores pós-keynesianos, argumenta Lavoie (2014), enfatizam o caráter oligopolizado das economias modernas, considerando a definição de mark-up como regra de formação de preços, em ambiente de incerteza. Já Marx (1894) mostra que a concorrência leva à centralização e concentração em razão do imperativo no nível microeconômico, para cada capital individual, da acumulação de capital em geral e do desenvolvimento tecnológico.

O papel da moeda nas economias capitalistas torna-se fundamental para as ações dos agentes econômicos, ao invés de ser um véu sobre as transações reais, justamente porque, mesmo de forma conflituosa e podendo conduzir a instabilidade e crises, é ela que articula e coordena o andamento da economia. A moeda não

\footnotetext{
18 Bresser-Pereira (2012) aponta que os neoclássicos seguem o método hipotético-dedutivo, que é fundado em abstrações teóricas sem aplicação prática e não pode ser demonstrado histórica ou empiricamente. Já autores como Marx e Keynes integram grupo de economistas que se utilizaram do método histórico-dedutivo, com arcabouços teóricos criados, de maneira aberta, pela observação de regularidades e tendências historicamente.
} 
é neutra, nem no curto nem no longo prazo, e é endógena na economia. Os dois autores, assim, refutam a Lei de Say e a Teoria Quantitativa da Moeda, como destaca Mollo (2003). Tanto para Marx quanto para Keynes a moeda é um fenômeno social que une os indivíduos na sociedade capitalista. A divisão social do trabalho implica a validação social do trabalho privado somente pelo dinheiro, para os marxistas, ao mesmo tempo em que o crédito é indissociável do processo de acumulação, influenciando a natureza própria do capitalismo. Em Keynes, a moeda decorre da necessidade que surge da incerteza e das funções que exerce, e pode acalmar ou não os agentes, influenciando a preferência pela liquidez na economia, variável essencial que, por seu turno, estabelece, junto com a eficiência marginal do capital, o nível de investimento na economia ${ }^{19}$. A moeda, nas duas perspectivas, não pode ser neutra, pois é um bem desejado, sem que isso signifique ilusão monetária, uma vez que a forma dinheiro ou moeda é a expressão de riqueza universal e poder de compra puro, diferentemente de bens particulares ou riquezas específicas em determinados usos.

O papel do Estado na economia é visto como relevante para as duas abordagens. O papel das políticas fiscal e monetária e do Estado no crescimento pode ser ativo, sem que os efeitos dessas políticas sejam neutralizados com o tempo, como defendem autores neoclássicos, em razão dos supostos efeitos do crowding-out e da Teoria Quantitativa da Moeda, conforme ressaltam Mollo e Fonseca (2013).

Mollo (2001) observa que os marxistas ${ }^{20}$ reconhecem o Estado como Estado de classe. Ele é ator importante do sistema capitalista, principalmente na regulação estatal de duas mercadorias essenciais, a força de trabalho e o dinheiro. Apesar de ser um Estado de classe, ainda assim, a partir de argumentos desenvolvidos por Poulantzas, é possível verificar certa autonomia do Estado perante as classes sociais, o que pode constituir oportunidade para os trabalhadores pressionarem por melhorias no bem-estar e regulação para melhorar a situação do emprego e do crescimento da economia e de sua inserção social. Mesmo apontando as limitações do Estado burguês, que atua para salvar a economia cuja lógica pune os trabalhadores e não tem como superar definitivamente as crises que surgem da dinâmica econômica, os marxistas admitem que as possibilidades abertas com a melhoria das condições de vida e do emprego permitem contexto mais adequado para barganhas salariais e desenvolvimento de ações coletivas.

Davidson (1991) salienta que os pós-keynesianos defendem papel pronunciado do Estado para a estabilização e o crescimento na economia. O governo pode ter visão mais ampla sobre as necessidades da comunidade, enquanto agentes privados

\footnotetext{
${ }^{19}$ Em razão do tempo histórico e da incerteza, o investimento, causa causans da determinação do nível de demanda efetiva segundo Keynes (1936), pode acabar restringido, gerando limites monetários ao crescimento, como aponta Amado (2000).

${ }^{20}$ De acordo com Mollo (2001), nos debates entre os marxistas existem correntes que não veem possibilidade de melhoria por meio da atuação via Estado, com base na contribuição de Miliband, para quem o Estado é mero braço da burguesia.
} 
são mais motivados por oportunidade de lucro rápido. O governo é importante na determinação da escala das operações de investimento de longo prazo com benefícios sociais acima das perspectivas de lucro privado, atuando, portanto, na ausência de incentivos privados. Keynes (1936) argumentava em favor da socialização do investimento promovida pelo governo, para assegurar aproximação ao pleno emprego. Embora não observem os limites à atuação estatal previstos pelos marxistas, os pós-keynesianos ressaltam que o papel do governo é criar um ambiente que reduza fortemente os defeitos do sistema econômico sem eliminar suas vantagens.

Partindo de uma noção de que o ambiente socioeconômico precede e interfere nos comportamentos econômicos dos agentes, o Estado pode ter um papel na gestão desse ambiente, por meio de políticas econômicas. Com efeito, a formação de um ambiente macroeconômico adequado torna-se necessária para o desenvolvimento econômico. Para isso, o Estado tem papel fundamental para a heterodoxia. Mollo e Teixeira (2008) argumentam, utilizando influências heterodoxas que incluem Marx e Keynes, que as capacidades macrodinâmicas são fundamentais. A ênfase da literatura sobre capacidades dinâmicas recai frequentemente sobre a análise microeconômica, mas a promoção de mudanças estruturais requer uma perspectiva macroeconômica, em que um contexto macrodinâmico apropriado ao progresso econômico e social exerce influência decisiva. Os autores $(2008$, p. 267) destacam

the importance of a macroeconomic and institutional foundation linking investment, technology and the macro-management of the economy. Prosperity cannot be regarded as natural and expected as a matter of course. Nor can it be characterized by an afflux of new technology, business organization, financial flows, or whatever, unless institutional environment and historical conditions are proper.

Seja para melhor gerir as condições de incerteza, no caso keynesiano, ou para melhorar a inserção social dos trabalhadores na relação capital-trabalho, no caso marxista, algumas linhas de política econômica podem, como sugerido por Mollo e Teixeira (2008), ser buscadas para a sustentação de ambiente que se coadune aos fundamentos macroeconômicos verificados nas economias capitalistas. São relevantes uma estrutura adequada de juros reais para estimular o investimento; uma estrutura de orçamento sustentável sem dívida excessiva, com reestruturação da dívida pública sem pressionar a taxa de juros; uma taxa de câmbio competitiva; um Banco Central com foco na estabilidade financeira, mas também na produção e no emprego; controle prudencial do sistema bancário para evitar fragilidade financeira; e regulação estatal para inibir a supremacia financeira sobre a produção. Também a criação de condições institucionais de demanda, regulação e aprendizado propicia capacidades macrodinâmicas importantes no sistema econômico. Nesse sentido, são apontados a prioridade ao crescimento com melhor distribuição de renda e riqueza; geração de empregos para absorver mão de obra qualificada e 
menos qualificada do exército industrial de reserva; criação de sistema de seguridade de massa; reforma do sistema tributário para reduzir incidência de impostos sobre classes de menor renda; e estratégias de longo prazo para financiar projetos de investimento públicos, principalmente em infraestrutura, saúde, educação e P\&D.

\section{COMENTÁRIOS FINAIS}

Os fundamentos microeconômicos na abordagem ortodoxa podem ser revistos com base em argumentos presentes até na escola neoclássica. No entanto, os conceitos e a formulação teórica trazidos por Marx e Keynes elucidam aspectos essenciais do sistema capitalista que tornam necessário o entendimento de fundamentos macroeconômicos para o comportamento microeconômico. As abordagens marxista e pós-keynesiana definem o papel e o comportamento dos agentes econômicos a partir de um contexto macro, respectivamente, a evolução capitalista fundada na lei do valor ou permeado pela incerteza que perpassa as decisões econômicas em economias monetárias. Essas abordagens heterodoxas permitem compreensão mais ampla da complexidade existente no capitalismo.

As noções avançadas por Marx e Keynes são úteis ao entendimento das limitações ao desenvolvimento econômico no capitalismo e à avaliação da pertinência de políticas econômicas conducentes ao crescimento ou que mitiguem os efeitos da instabilidade e da desigualdade inerentes ao sistema. Diferentemente da perspectiva neoclássica, que não admite intervenções estatais ou as delimita a momentos de estabilização de curto prazo, as duas correntes heterodoxas reconhecem possibilidades de atuação concreta do Estado no desenvolvimento, em particular para agir sobre o contexto macroeconômico que afeta o comportamento dos agentes.

\section{REFERÊNCIAS BIBLIOGRÁFICAS}

AMADO, A. M. (2000) "Limites monetários ao crescimento: Keynes e a não-neutralidade da moeda". Ensaios FEE, vol. 21; pp.44-81.

AMADO, A. M. (1992) "O real e o monetário em economia: traços ortodoxos e heterodoxos do pensamento econômico”. In: SILVA, M. L. (Org.). Moeda e produção: teorias comparadas. Brasilia: Editora Universidade de Brasilia.

BELLOFIORE, R. (2004) "Marx and the macro-monetary foundation of microeconomics". In: BELLOFIORE, R.; TAYLOR, N. The constitution of Capital. Gordonsville: Palgrave.

BRESSER-PEREIRA, L. C. (2012) "For a heterodox mainstream economics: an academic manifesto". Journal of Post-Keynesian Economics, vol. 35 (1), p. 3-20.

BRESSER-PEREIRA, L. C.; LIMA, G. T. (1996) "The irreductibility of macro to microeconomics: a methodological approach”. Revista de Economia Política, vol. 16, nº 2 (62), pp. 16-39, abril-junho.

BRUNHOFF, S. (1976 [1978]) A moeda em Marx. Rio de Janeiro: Paz e Terra.

CARVALHO, F. C. (1992) Mr. Keynes and the Post Keynesians. Aldershot: Edward Elgar.

CHICK, V. (1983) Macroeconomics after Keynes. MIT Press: Cambridge.

CHICK, V. (2003) "Theory, method and mode of thought in Keynes's General Theory". Journal of Economic Methodology, 10 (3):307-327. 
DAVIDSON, P. (1972) Money and the Real World. New York: Wiley.

DAVIDSON, P. (1991) “The neoclassical vs. post keynesian view of government". In: DAVIDSON, P. Controversies in Post Keynesian Economics. Edward Elgar: Aldershot, UK - Brookfield, US.

DOW, S. (1996) The methodology of macroeconomic thought: A conceptual analysis of schools of thought in economics. 2nd ed. Cheltenham \& Northampton: Edward Elgar.

DUARTE, P. G.; LIMA, G. T. (2012) "Privileging micro over macro? A history of conflicting positions." In: DUARTE, P. G.; LIMA, G. T. (Eds.). Microfoundations reconsidered: The relationship of Micro and Macroeconomics in Historical Perspective. Cheltenham: Edward Elgar.

HAHN, F. (2003) "Macro foundations of micro-economics". Economic Theory 21, p. 227-232.

HOWARD, M. C.; KING, J. E. (2001) "Where Marx was right: towards a more secure foundation for heterodox economics". Cambridge Journal of Economics, vol. 25(6), pages 785-807, November.

HOOVER, K. D. (2012) Microfoundational Programs. In: DUARTE, P. G.; LIMA, G. T. (Eds.) Microfoundations reconsidered: The relationship of Micro and Macroeconomics in Historical Perspective. Cheltenham: Edward Elgar.

ITOH, M.; LAPAVITSAS, C. (1999) Political economy of money and finance. London: Macmillan.

JAY, M. (1984) Marxism and totality. Berkeley and Los Angeles: University of California Press.

KEYNES, J. M. (1933 [1973]) "The distinction between a co-operative economy and an entrepreneur economy”. In: The Collected Writings of JMK, vol. XXIX, pp. 81-83. Cambridge: Macmillan.

KEYNES, J. M. (1937 [1987]) "The General Theory of Employment". In: The Collected Writings of $J M K$, vol. XIV, pp. 109-123. Cambridge: Macmillan.

KEYNES, J. M. (1936 [1964]) The general theory of employment, interest and money. Harcourt: New York.

KIRMAN, A. P. (1992) "Whom or what does the representative individual represent?" Journal of Economic Perspectives, 6, p. 117-136.

KREGEL, J. (1987) "Rational spirits and the post-keynesian macrotheory of Macroeconomics". De Economist, vol. 135, nr. 4, 520-32.

LAVOIE, M. (2014) Post-Keynesian economics: New foundations. Cheltenham: Edward Elgar.

LUCAS, R. (1976) "Econometric Policy Evaluation: A Critique”. In: K. BRUNNER; MELTZER, A. (eds.). The Phillips Curve and Labor Markets. Carnegie-Rochester Conference Series on Public Policy, Volume 1, pages 19-46.

LUKÁCS, G. (1984 [2012]) Para uma ontologia do ser social I. São Paulo: Boitempo.

MARX, K. (1857/58 [2011]) Grundrisse. São Paulo: Boitempo.

MARX, K. (1867 [1998]) O Capital: crítica da economia política. Livro I. Rio de Janeiro: Civilização Brasileira.

MARX, K. (1885 [1998]) O Capital: crítica da economia política. Livro II. Rio de Janeiro: Civilização Brasileira.

MARX, K. (1894 [1998]) O Capital: crítica da economia política. Livro III. Rio de Janeiro: Civilização Brasileira.

MOLLO, M. L. R. (2001) "A concepção marxista de Estado: considerações sobre antigos debates com novas perspectivas”. Economia (Brasília), ANPEC, vol. 2, n. 2, p. 347-389, jul/dez.

MOLLO, M. L. R. (2003) “Moeda, taxa de juros e preferência pela liquidez em Marx e Keynes” In: LIMA, G. T.; SICSÚ, J. (orgs.) Macroeconomia do emprego e da renda: Keynes e o keynesianismo. Barueri, SP: Manole.

MOLLO, M. L. R. (2011) “Crédito, capital fictício, fragilidade financeira e crises: discussões teóricas, origens e formas de enfrentamento da crise atual”. Economia e Sociedade, Campinas, v. 20, n. 3 (43), p. 449-474, dez.

MOLLO, M. L. R.; FONSECA, P. C. D. (2013) "Desenvolvimentismo e novo-desenvolvimentismo: raízes teóricas e precisões conceituais”. Revista de Economia Política, vol. 33, nº 2 (131), pp. 222-239, abril-junho.

MOLLO, M. L. R.; TEIXEIRA, J. (2008) "Macrodynamic capability: concept and monetary and financial conditions”. In: LEONCINI, R.; MONTRESOR, S. (Orgs.). Dynamic Capabilities between Firm Organization and Local Systems of Production. Abingdon/New York: Routledge. 
POSTONE, M. (2008) "Rethinking Capital in light of the Grundrisse.” In: MUSTO, M. (ed.) Karl Marx's Grundrisse: Foundations of the critique of political economy 150 years later. Abingdon/ New York: Routledge.

POSTONE, M. (1993) Time, Labor, and Social Domination: A Reinterpretation of Marx's Critical Theory. New York: Cambridge University Press.

SAAD FILHO, A. (2002) The Value of Marx. London and New York: Routledge.

SCREPANTI, E.; ZAMAGNI, S. (2005) An Outline of the History of Economic Thought. New York: Oxford University Press.

WEINTRAUB, S. (1956) "A macroeconomic approach to the theory of wages." The American Economic Review, Vol. 46, No. 5, p. 835-56, Dec. 